Active interest mentorship for soon-to-retire people: A self-sustaining retirement preparation program

Siu-man Ng, Lingli Leng, Qi Wang

The University of Hong Kong

Author Note

This research was funded by the Hong Kong Jockey Club Charities Trust, and implemented in collaboration with the Hong Kong Christian Service (HKCS).

Correspondence concerning this article should be addressed to Dr. Siu-man Ng, Associate Professor, Department of Social Work \& Social Administration, The University of Hong Kong, Pokfulam, Hong Kong. Email: ngsiuman@hku.hk 


\begin{abstract}
Retirement is a major life transition that often leads to maladjustments and mental health hazards. In this study, we developed an innovative retirement preparation program, the Active Interest Mentoring Scheme (AIMS), which utilized active interest development as a positive entry point through which to engage soon-to-retire people. Each retiree received a one-year mentorship six months before retirement. Adopting a quasi-experimental design, the study aimed to evaluate the efficacy of the AIMS in protecting retirees' well-being. The well-being status of 161 retirees was assessed at four-month intervals. Measures included self-esteem, life satisfaction, positive affect, depression, anxiety, and somatic symptoms. Serial trend analysis revealed a general improvement in well-being at four months after mentorship, followed by a mark reversion in some variables at two months after retirement. Upon completion of the program, participants generally returned to a level of well-being that was comparable to or better than pre-retirement levels. The first two months after retirement appeared to be the most distressing. The findings support the efficacy, as well as feasibility of the innovative retirement preparation program.
\end{abstract}

Keywords: retirement transition, adjustment, intervention 


\section{Active interest mentorship for soon-to-retire people: A self-sustaining retirement}

\section{preparation program}

\section{Introduction}

Retirement is one of the most important milestones in the later life of working adults (Wang, Koo, \& O'Hare, 2016). According to the Information Services Department of Hong Kong (2014), people aged 65 or above constituted 13\% of the Hong Kong population in 2014. It is projected that this number will increase to $19 \%$ by 2020 and $30 \%$ by 2041 . The modal age of retirement is between 50 and 65 and there are about 60,000 working adults entering retirement every year in Hong Kong. As the population ages, life after retirement has attracted growing public attention (Wang, Koo, \& O'Hare, 2016).

Retirement is commonly defined as an individual's exit from the workforce, as well as the withdrawal from job positions psychologically and behaviorally (Shultz \& Wang, 2011, Wang \& Shi, 2014). Retirement is a significant life transition that involves role changes and redefinition, life styles changes, relationship changes and activity shifts (Kim, Moen, 2001; Vo et. al., 2014). It may lead to both positive and negative mental health outcomes (van Solinge \& Henkens, 2008; Clarke, Marshall, House, \& Lantz, 2011; Dow \& Meyer, 2010; Byles et al., 2013; Hardy, 2002).

Previous studies have revealed the positive impacts of voluntariness of the retirement (Reitzes \& Mutran, 2004; van Solinge \& Henkens, 2007, 2008) and retirement planning (Petkoska \& Earl, 2009; Reitzes \& Mutran, 2004; Wang, 2007) on retirees' psychological well-being. People who are actively engaged in leisure or other non-work related activities 
showed better mental health status (Quick \& Moen, 1998, Dorfman \& Douglas, 2005; Kim \& Feldman, 2000). Ideally, if there is an effective universal retirement preparation program in place, the majority retirees can successfully navigate the major transition in life, and proceed to a fruitful third age. As tens of thousands of people retire every year, such a program must not only be effective, but also acceptable, affordable, and sustainable over time. In response to this challenge, we developed an innovative retirement preparation program called the Active Interest Mentorship Scheme (AIMS).

Mentoring is a crucial component in this program. The term mentor often refers to the supporting role model in a profession that is highly admired and appreciated by mentees (Freedman, 2009). In the present research, mentor is considered as an individual who is willing to befriend and share their retirement experiences with soon-to-retire people (Freedman, 2009). The relationship between mentors and mentees is more reciprocal, rather than providing one-way guidance to mentees and considering them as in vulnerable situations (Lindbo \& Shultz, 1998).

Some studies have explored the role of mentoring in the workforce. For examples Wilson (2015) examined the potentials of active mentoring in supporting the transition into retirement for older people with a disability. The program they developed later demonstrated that mentorship was helpful to these retirees in developing an adaptive lifestyle after retirement (Stancliffe, Bigby, Balandin, Wilson, Craig, 2015). Koc-Menard (2009) highlighted the benefits for corporates to make use of the mentors' knowledge and experience to train successors, and systematically develop its capacity in supporting retirees. Some 
studies focused on the effectiveness of senior mentors who are retired in coaching the younger generations in their professional development (Bates, Cohan, Bragg, \& Bedinghaus, 2006; Wieland, \& Eleazer, 2008; Eleaze, Wieland, Roberts, Richeson, \& Thornhill, 2006; Eleazer, Stewart, Wieland, Anderson, \& Simpson, 2006; Hoffman, Gray, Hosokawa, \& Zweig, 2008). Up till now, mentoring specifically for retirement preparation is yet to be rigorously evaluated. AIMS is an attempt to systematically use mentors in retirement preparation. To enhance its acceptability, AIMS strategically employs active interest development to engage the soon-to-retire people. This paper deliberates the rationales in conceiving AIMS, and reports the experiences and outcomes in implementing the program.

\section{Literature Review}

\section{Active Interest}

Previous studies have explored the relationship between retirement transition and retiree's social roles and network (Heaven, Brown, White, Errington, Mathers, \& Moffatt, 2013; Hershey \& Henkens, 2014; Houlfort et al., 2015). Among the protective factors, the strongest are, before retirement, having satisfying familial relationships and active passionate interests (Kojala \& Moen, 2016). From a practical point of view, a focus on marital or familial relationships is not feasible. With an embedded negative connotation of labelling retirees having relationship problems, the program would be acceptable to few potential participants. Moreover, intervening in relationship problems is overly intensive for a program intending to act as a universal retirement preparation service.

Active interest development before retirement appears to be a more appealing entry point 
for engaging soon-to-retire people. Active interest differs from passive interest in the sense that the people involved are actors, rather than watchers (Stebbins, 2013). Examples of active and passive interests include playing versus watching soccer, making movies versus going to the cinema, and writing stories versus reading novels. All different types of active interests share a common feature, in that they are more engaging and demanding than passive interests, but are also intrinsically more satisfying and rewarding (Nathan, Wood, \& Giles-Corti, 2013). Whereas passive interests and sedentary lifestyle have been explored by various researchers (Touvier, Bertrais, Charreire, Vergnaud, Hercberg, \& Oppert, 2010), active interests seem to have received less attention. To enhance its appeal to the soon-to-retire people, the AIMS program strategically focuses on supporting the retirees to develop active interest. However, it is important to emphasize that the program does not to devaluate passive interest. Indeed. it is common and rewarding for individuals to pursue both active and passive interests in parallel.

Active interests have also been shown to have strong protective value to the mental health of people going through retirement (Matz-Costa, Besen, Boone James \& Pitt-Catsouphes, 2014; Earl, Gerrans, \& Halim, 2015). The salubrious effect of active interests can be understood from the perspectives of role theory, continuity theory, and activity theory (Wang, 2007). Role theory, which focuses on role exit and transition (Wang, Henkens, \& van Solinge, 2011), is one of the core theoretical perspectives that explains the challenges of retirement and the adjustment process (Riley \& Riley, 1994). In this theory, retirement is seen as an exit from a working role and a transition to a non-working role. 
Gainful employment often plays a fundamental role that is essential to an individual's self-concept, esteem, and social identity (Kim \& Moen, 2002). In other words, losing a working role can negatively affect one's self-concept, esteem, and social identity (Riley \& Riley, 1994). If a retiree has a passionate active interest and feels proud of being devoted to it, that retiree may find a powerful, positive substitute to a working role.

Continuity theory emphasizes the consistency of individuals' roles and life patterns after retirement (Atchley, 1999). According to Atchley (1999) and Wang (2007), if retirees can maintain reasonable levels of continuity in self-identity and life patterns, they will likely also be able to maintain their overall well-being (Duberley, Carmichael, \& Szmigin, 2013). Having a passionate active interest before retirement and becoming even more devoted to that interest after retirement provides a continued platform for maintaining consistent social roles and life patterns.

Activity theory underscores the continuous development of retirees (Armstrong-Stassen, 2007; Kraimer et al., 2011). It advocates that people should remain active in various areas and activities as far as possible in old age (Charles \& Carstensen, 2010; Bal et. al., 2011). Maintaining activity leads to better life satisfaction and physical health (Rowe \& Kahn, 1997). While bridge employment after retirement helps individuals to retain high levels of activity, it is not an option for many retirees. Compared with bridge employment, active interests are a more long-term choice.

\section{Mentoring}

Mentoring is another important component in the AIMS program. The term mentoring 
can be traced back to the Greek mythology in Homer's Odyssey (Freedman, 2009). In Odyssey, Mentor was the teacher of Telemachus who is the son of Odysseus and Mentor instructed Telemachus when Odysseus was not at home (Lindbo \& Shultz, 1998). Nowadays in daily language, mentor refers to "a confidant, an adviser, a teacher, a guide, a coach, and a role model" (Lindbo \& Shultz, 1998, p. 54). Major functions of the mentor-mentee relationship include teaching, personal support and organizational intervention (Zey, 1991). Most researchers emphasize the role of mentoring in passing on experience and knowledge from experts to new-entries, and the benefits to corporates adopting a mentoring system (Lindbo \& Shultz, 1998; Freedman, 2009, Koc-Menard, 2009).

There has been a trend in medical schools to incorporate mentoring in supporting the professional development of trainees and junior practitioners (Stewart \& Alford, 2008; Heflin, 2008; Hoffman, Gray, Hosokawa \& Zweig, 2008; Thornhill, Richeson, \& Roberts, 2002; Eleazer, Steward, Wieland, Anderson \& Simpson). Previous studies have revealed the positive impacts of mentoring in facilitating students getting deeper insights of the subject matters, and developing holistic understanding of patients.

Application of mentoring specifically in retirement application is yet be rigorously implemented and evaluated. In light of the theoretical merits, AIMS systematically incorporates mentoring, together with active interest development, into a retirement preparation program. Mentoring is an interactive process between the mentor and mentee. In sharing their experience with their mentees, the mentors may also benefit, for examples feeling being valued and becoming more socially active. Whereas for the mentees, they have 
someone there to listen to them, share their feelings, discuss their retirement planning, introduce retirement experience and offer emotional support. The process creates an atmosphere facilitating mutual understanding and support.

\section{Design and Methods}

\section{Building up the mentor pool}

Grounded on consistent research findings on the strong protective value of active interests in retirement, the AIMS adopted the theme of developing active interests before retirement for a more satisfying retirement. Solely relying on professionals' input to prompt and sustain behavioral changes among the retirees is impractical and overly expensive (Sosik \& Godshalk, 2000). Therefore, the AIMS incorporated a mentoring component. Retired people who are willing to share their own experiences and knowledge of retirement were trained to become mentors. While active interest development was a central theme, the mentor-mentee relationship also provided a natural platform for the soon-to-retire people to share their experiences and seek advice during the retirement transition. Moreover, upon completion of the mentorship service, successful retirees could be recruited and trained to become new mentors. The mentor pool will have natural organic growth, thereby greatly enhancing the affordability and sustainability of the AIMS.

\section{The Active Interest Mentorship Scheme}

Prior to the current study, a pilot trial with 10 retirees and 10 mentors was conducted. A key objective was to develop the necessary program materials, which included a four-session training workshop for mentors, a guidebook for mentees, and a resource booklet of active 
interests. Our team developed an eight-dimension attributional model of active interests for assisting soon-to-retire people in identifying active interests that align with their personal orientations. The eight dimensions are: (1) physical challenge; (2) stillness; (3) intellectual challenge; (4) cooperative task; (5) solo task; (6) philanthropic endeavor; (7) spiritual pursuit; and (8) creativity and artistic appreciation. An activity can have multiple attributes. For example, cycling can be physical, cooperative and/or independent, yoga can fulfil the attributes regarding physical, stillness, being cooperative and/or independent, and spiritual, and astronomy can fulfil the attributes regarding stillness, being intellectual, and being cooperative and/or independent. We developed a simple computer program to filter out active interests in accordance with the specified attributes.

A matching process for pairing up mentors and mentees was developed and refined in the pilot study. Each trained mentor was matched with one to two mentees, primarily based on their indicated gender preference and geographic distance. Mentor-mentee matching evenings were conducted regularly in order to welcome soon-to-retire people who were new to the program, and to facilitate their first meeting with their respective mentors.

The project officer, who is a registered social worker, organized monthly group supervisions for mentors. In between monthly supervisions, the project officer was available and accessible for mentors for consultation on issues encountered in the course interaction with their mentees. The mentor-mentee relationship nominally lasted for one year, from half a year before the retirement to half a year after the retirement of the mentee. Mentors and mentees had full discretion in deciding whether or not they wanted to continue their 
friendships after the nominal one-year mentorship period.

After the pilot study, a quasi-experimental design was adopted. In line with the one-year mentorship design of the AIMS, four waves (T1, T2, T3, and T4) of the survey were conducted with each mentee at four-month intervals. T1 was conducted about six months before retirement and $\mathrm{T} 4$ was conducted six months after retirement. The actual retirement took place between T2 and T3. The four-wave survey design aimed to track changes in the well-being of mentees in the retirement transition. Measures included both positive and negative measures; namely, self-esteem, life satisfaction, positive affect, depression, anxiety, and multiple somatic symptoms. We hypothesized that, upon completion of one year of mentorship, retirees' well-being would be preserved.

\section{Ethical Approval}

The ethical approval of the study was granted by the Human Research Ethics Committee for Non-Clinical Faculties, The University of Hong Kong. The best research practice was observed, in particular in regard to respecting the rights of the mentees. Informed written consent was obtained from all participants prior to intervention and data collection.

\section{Participants}

Participants were recruited with the collaboration of an employee assistance program NGO in Hong Kong. Invitation letters were sent to the human resource departments of the corporate clients of the NGO. The human resource departments then helped convey the invitation to staff due to retire within one year. Subsequently, 200 soon-to-retire people gave informed consent and participated in the study. Except the AIMS program, these 
soon-to-retire participants did not join other retirement and lifestyle advice programs. Among them, 161 mentees completed the one-year mentorship and four waves of survey. The completion rate of mentees was thus $80.5 \%$. The analysis sample included 92 men and 69 women. Of these, $18.6 \%$ were ages $50-54,32.3 \%$ were ages $55-59$, and the other $49.1 \%$ were ages 60-65. Regarding educational level, the majority of mentees had over 10 years of education, with $3.1 \%$ having attained education to a primary school level, $39.8 \%$ to a secondary school level, $42.9 \%$ to a college or university level, and $14.2 \%$ to a postgraduate level. Participants' years of tenure with their last employer were $15.5 \%$ under 10 years, $55.9 \%$ between 10 and 20 years and $33.5 \%$ over 20 years. Their positions upon retirement were $31.1 \%$ in support/frontline grades, $28.0 \%$ in junior supervisory grades, $19.3 \%$ in middle/upper managerial grades, and $21.7 \%$ in professional grades.

In Hong Kong, retirement age depends very much on the occupation. The normal retirement age is 60 for civil servants, and 55 to 57 for disciplined service officers (Administration of the Civil Service, 2016). In the private sector, the retirement age is more flexible. The modal range of Hong Kong citizens' retirement age is between 50 and 65, which is consistent with the age profile of the participants of the current study.

\section{Procedures}

As mentioned above, the soon-to-retire people received information of the AIMS via the human resource department of their respective companies. Those interested in learning more indicated their initial interest in the AIMS by returning a simple reply slip to us. Subsequently, they had an individual meeting with our project officer. Written informed consent was 
obtained from all mentees prior to intervention and data collection. New mentees were arranged to attend the nearest scheduled mentor-mentee matching evening, during which they would meet their mentors. The nominal period of mentorship was one year, from about six months before retirement to about six months after retirement. The mentees had access to the project officer, who was a registered social worker, whenever they felt the need for advice, including retirement planning and psychosocial issues such as family relationship problems. Measures on the well-being status of every mentee were taken at four time points, as described earlier. Upon completion of the one-year mentorship, we invited the ex-mentees to join the AIMS as mentors. Interested ex-mentees would go through our mentor training workshop.

\section{Measures}

Previous studies suggest that continued activities may enhance the well-being of retirees, for examples, in life satisfaction (Antonucci, 2001; Heckhausen \& Schulz, 1995; Lyubomirsky, Sheldon, \& Schkade, 2005; Nimrod \& Kleiber, 2007; Tkach \& Lyubomirsky, 2006), and emotional, cognitive and social competence (Pushkar, Arbuckle, Conway, Chaikelson, \& Maag, 1997). In light of these findings, some relevant positive measures, such as self-esteem, life satisfaction and positive affect were included in the study. Since previous studies have also revealed that people during retirement transition are at risk of mental health problems. Some relevant negative measures, such as anxiety, depression and multiple somatic complaints were included. The combination of positive and negative measures can 
help reduce response bias and improve research validity (Sonderen, Sanderman, \& Coyne, 2013). The measures included in the study are depicted below.

The Rosenberg Self-Esteem Scale (Rosenberg, 1965) is a 10-item scale assessing levels of self-esteem. The items on the scale are answered on a 4-point Likert scale, from 1 (strongly agree) to 4 (strongly disagree). Higher scores indicate a greater level of self-esteem, with the nominal range falling between 15 and 25 . Internal consistency for the total scores was .92 , and test-retest reliability over a period of two weeks was between .85 and .88 .

The Satisfaction with Life Scale (Diener, Emmons, Larsen, \& Griffin, 1985) is a 5-item scale assessing global cognitive judgments of life satisfaction. This scale showed good sensitivity in detecting changes in life satisfaction level throughout the course of clinical intervention (Pavot \& Diener, 1993). Responses are given on a 7-point Likert scale, from 1 (strongly disagree) to 7 (strongly agree). The nominal range fell between 21 and 30 .

The Hospital Anxiety and Depression Scale (Snaith, 2003) is a 14-item scale assessing anxiety and depressive states. The scale was originally designed for physicians in the setting of medical practices, for screening purposes. Studies have shown that the scale is also valid in community and primary healthcare settings as a screening instrument for depression and anxiety levels. The normal scores range was between 0 and 7 for both the depression and anxiety subscales.

The 14-Item Physical Distress Scale (Ng, Yau, Chan, Chan, \& Ho, 2005) is a measure of subjective appraisal of multiple somatic complaints. Internal consistency of the total scores 
was .87. Responses are given on an 11-point scale with higher scores representing greater concerns.

The Positive Affect Scale (Ng et al., 2005) is a 9-item scale measuring the levels of positive affect that the participants have experienced over the past week. Internal consistency of the total scores was .88. The items include feelings of happiness, ease, and confidence.

The reliability of these measures was re-examined in this study by Cronbach's Alpha $(\alpha)$. The results suggested good internal consistency, with $\alpha$ between .91 and .96 .

\section{Results}

Data analyses were performed with SPSS v.22 (I.B.M. Corp, 2013). The results of various well-being measures from $\mathrm{T} 1$ to $\mathrm{T} 4$ are summarized in Table 1 . To evaluate the changes in these measures from $\mathrm{T} 2, \mathrm{~T} 3$, and $\mathrm{T} 4$ over $\mathrm{T} 1$, paired sample t-tests were performed (Table 2).

\section{$<$ Please insert Table $1 \& 2$ here>}

In order to further explore the patterns of changes in various well-being measures, the percentages of score changes at T2, T3, and T4 over T1 were computed and named $\mathrm{C} 1, \mathrm{C} 2$, and C3, as shown in Figure 1. At T2, four months after mentorship, there was a general improvement in well-being among the mentees, as reflected by an overall decreasing pattern in negative measures and an increase in positive measures. At T3, about two months after retirement, there seemed to be a reversion in the overall well-being of the mentees. At T4, upon completion of the one-year mentorship, mentees appeared to return to well-being comparable to or better than pre-retirement levels. 
At T2, four months after the mentorship program, there was a general improvement in well-being among the mentees. In particular, there were significant increases in self-esteem and positive affect, and a decrease in multiple somatic complaints. Previous studies have revealed that proactive pre-retirement planning offers benefits to the psychological functions of the soon-to-retire people (Taylor \& Doverspike, 2003; Yeung, 2013). The senior mentors of the AIMS engaged the mentees and enabled them to take the necessary actions and make behavioral changes, in particular, in developing a passionate active interest before retirement. Intensive mentorship seems to have contributed to the observed improvement in the well-being of the mentees.

At T3, about two months after retirement, the positive changes at $\mathrm{T} 2$ tended to be reversed as indicated in the serial trend analysis. As shown in Figure 1, the decreasing pattern in negative measures from $\mathrm{T} 1$ to $\mathrm{T} 2$ was reversed at $\mathrm{T} 3$. From $\mathrm{T} 2$ to $\mathrm{T} 3$, significant increases in depression, anxiety and multiple somatic complaints were observed. Moreover, a significant decrease in satisfaction with life also emerged. These observations suggest that the first two months after retirement are especially distressful for retirees. These findings are consistent with the patterns revealed in previous studies (Leinonen, Lahelma, \& Martikainen, 2013).

At T4, upon completion of the one-year mentorship, mentees appeared to return to well-being comparable to or better than pre-retirement levels. In particular, there were significant increases in positive affect and decreases in multiple somatic complaints. Depression and anxiety also returned to T2 levels. 
$<$ Please insert Figure 1 here $>$

\section{Discussion}

The aim of the current study is to evaluate the effectiveness of the AIMS program in maintaining the well-being of the soon-to-retire people going through the retirement transition. The one-year serial trend analysis suggests that the AIMS program helped enhance positive affect, preserve participants' self-esteem and life satisfaction, contain depression and anxiety, and reduce multiple somatic complaints. Adopting the development of active interests as a positive entry point, the AIMS was shown to be acceptable to the retirees. A completion rate of $80.5 \%$ among mentees is highly respectable for a one-year mentorship program. Moreover, using trained senior mentors ensured the intervention was intensive enough to produce real behavioral changes. One point should be noted is that in the current study, participants were recruited through the human resources department of corporates. That might have partly contributed to the good acceptability of the program. Future research should include participants working in smaller corporates or being self-employed. In such context, multiple strategies are likely needed to recruit these participants and support them staying in the program.

The one-year four-wave data of the current study shows that participants' well-being status changed sharply shortly before and after retirement. Such rapid changes could hardly be revealed in larger scale longitudinal studies which adopted longer intervals between waves of survey. For example, the nationally representative longitudinal study in the U.S. revealed 
that around $70 \%$ of retirees experienced minimum mental health status changes throughout the eight-year period of retirement, whereas around $25 \%$ and $5 \%$ retirees respectively showed negative and positive changes in mental health status (Wang, 2007). Similar study conducted in Germany revealed similar patterns (Pinquart \& Schindler, 2007). Findings of the current study provide finer information on the trajectories of key well-being measures around retirement. Future longitudinal studies may incorporate more measuring time points during this unstable period so as understand these trajectories better.

Participants of the study did not show big changes in self-esteem level throughout the retirement process. The findings apparently differ from previous findings that leisure activities is associated with better self-esteem (Reitzes, Mutran, \& Verrill, 2015). The discrepancy may be largely due to differences in study design. Being a cross-sectional survey, Reitzes' findings are about a positive correlation between leisure activities and self-esteem among the soon-to-retire people. Whereas the current study, which adopted a prospective design, suggests that self-esteem level remained more stable than other well-being measures such as life satisfaction during the retirement process.

In contrary to self-esteem, life satisfaction appeared to be more fluctuating, with a mark drop at T3 (2 months after retirement) and a strong rebound at T4 (6 months after retirement). The positive relationship between active lifestyle in old age and personal life satisfaction has long been discussed (Lynott \& Lynott, 1996). A recent study has found that retirement releases more free time for "individuals to re-master their own agenda and to invest more time in social and relational activities" (Becchetti, Ricca, \& Pelloni, 2011, p. 480). However, 
before the newly released free time is well occupied, life satisfaction may suffer. In parallel, the mark increase in depression and anxiety at $\mathrm{T} 3$ may also have an impact on the trajectory of life satisfaction and the time lag in integrating leisure activities into post-retirement life. These findings indicate that the first few months following retirement are especially challenging and deserve special attention.

Previous studies have explored the linkage between leisure activities and subjective well-being (SWB). A meta-analysis by Kuykendall (2015) including 37 studies and 11,834 individuals concludes that there is a moderate association between leisure engagement and SWB. Newman (2013) developed a psychological model explaining how the promotion of leisure activity may enhance SWB. One of the pathways for better SWD is increase in positive affect. Pushkar's (2010) 2-year longitudinal study on 368 men and women revealed that involvement in activities was associated with increase in positive affect and decrease in negative affect. Findings of the current study suggest that the AIMS program may enhance and maintain positive affect from T2 thru T4. Preservation of positive affect may be a buffer and help participants going through the toughest period around T3.

Previous studies have revealed the increased risk of depression and anxiety during the retirement process (Waller, Kaprio, Korhonen, Tuulio-Henriksson, \& Kujala, 2016). Results of the current study echoed these findings, with an upsurge in depression and anxiety level at T3 (2 months after retirement). The AIMS program appears to have helped retirees ride over the challenges, with depression and anxiety levels went down again at T4. Activities might be a component explaining the protective value of the AIMS program (Mannen \& Faulkner, 
2013).

Recognizing the importance of retirement planning, the AIMS program emphasizes engaging the retirees early. The protocol is to have mentoring commencing 6 months before the actual retirement of each retiree. The arrangement may ensure retirees to take actions early to prepare for retirement. Another local study in Hong Kong with 90 retirees reveals that pre-retirement planning is predictive of positive changes in people's well-being after retirement (Yeung, 2013). However, motivating people to make efforts and take actions often demands rather intensive individualized input. The AIMS program can be a cost effective way of prompting actions.

\section{Theoretical Contribution}

A major theoretical contribution of the present paper is the 8-dimension attributional active interest model. Most of previous research focuses on the contributions of leisure activity to people's well-being and daily life functioning after retirement, but there are no systematic distinctions on the types of leisure activities and their varied functions and applications. For example, several researches explored the role of gardening and watching TV in elderly's life after retirement (Bhatti, 2006; Oestlund, Jonsson, \& Waller, 2010; Grajczyk \& Zollner, 1998). The AIMS program developed an 8-dimension attributional model capturing very diverse activities. Many of our participants found the attributional model helpful to them in identifying activities suitable to them. The attributional model may also provide a useful framework facilitating future more refined enquiries in this area.

\section{Practical Implications}


There are three notable practical implications revealed from the study. Firstly, adopting active interest development and mentorship, the AIMS program offers a viable model for policy makers, human resources administrators and mental health practitioners to address the adjustment needs of the soon-to-retire people. Secondly, many retirement preparation programs recruit people already retired. Results of the current study suggest that such practice is not satisfactory because the period shortly after retirement is the most challenging. It is desirable to engage the retirees before their actual retirement. The AIMS program demonstrated a workable approach to do it. Thirdly, since the mentor pool has organic growth, the AIMS program can be self-sustaining. Being less reliant on professional staff, the program is affordable and manageable to many corporates and mental health service providers.

\section{Limitations}

There are a number of limitations with the current study. In particular, from a research point of view, it is desirable to adopt a randomized controlled trial (RCT) design so that non-intervention effects, such as placebo and seasonal effects, may be estimated. It is also difficult to tell to what extent the trajectories of the well-being variables observed in the study was accounted for by the natural course of people going through retirement. However, ethics are a big consideration here, as the adverse effects of retirement maladjustments can be very long-term and, sometimes, irreversible. The risks to the participants in a no intervention control group can hardly be ignored and should not be underestimated.

As adjustment to retirement can be a long term experience. Some national study followed 
the retirees up to eight years (Wang, 2007). Future studies should look into the longer term impacts of the AIMS program. Qualitative research method can also be incorporated so as to compensate some of the limitations due to lack of control group. Participants' lived experience of receiving mentoring, and subsequently becoming next-generation mentors can be more deeply understood.

\section{Conclusion}

Despite some limitations, the findings of this study support the effectiveness of AIMS program to improve soon-to-retire peoples' well-being, more specifically in enhancing positive affect, preserving participants' self-esteem and life satisfaction, containing depression and anxiety, and reducing multiple somatic complaints. The research underscores the potentials of mentoring and active interest development in improving soon-to-retirees' mental health status. The 8-dimension attributional active interest model provides a useful framework for both researchers and mental health practitioners.

Last but not the least, we are delighted to share that, in our experience, about $40 \%$ of retirees who had completed the one-year mentorship expressed interest in re-joining the AIMS as mentors. Having a mentor pool with organic growth, the AIMS can be self-sustaining. These characteristics are important for a retirement preparation program intending to be a universal service, because there are tens of thousands people retiring every year. In light of the favorable results revealed in the current study, further rigorous studies on the AIMS are worth pursuing. 


\section{References}

Administration of the Civil Service (2016, Sep. 4). Retirement. Retrieved from http://www.csb.gov.hk/english/admin/retirement/183.html

Antonucci, T. C. (2001). Social relations: An examination of social networks, social support, and sense of control. In K. W. Schaie (Ed.), Handbook of the psychology of aging (5th ed.). (pp. 427-453). San Diego, CA US: Academic Press.

Armstrong-Stassen, M. (2007). Organizational practices and the post-retirement employment experience of older workers. Human Resource Management Journal, 18(1), 36-53. doi:10.1111/j.1748-8583.2007.00057.x

Atchley, R. C. (1999). Continuity and adaptation in aging: Creating positive experiences. Baltimore, MD: Johns Hopkins University Press.

Bal, P., De Jong, S., Jansen, P., \& Bakker, A. (2011). Motivating employees to work beyond retirement: A multi-level study of the role of I-deals and unit climate. Journal of Management Studies, 49(2), 306-331. doi:10.1111/j.1467-6486.2011.01026.x

Bates, T., Cohan, M., Bragg, D., \& Bedinghaus, J. (2006). The Medical College of Wisconsin Senior Mentor Program. Gerontology \& Geriatrics Education, 27(2), 93-103. doi: $10.1300 / \mathrm{j} 021 \mathrm{v} 27 \mathrm{n} 02 \_10$

Becchetti, L., Giachin Ricca, E., \& Pelloni, A. (2011). The Relationship Between Social Leisure and Life Satisfaction: Causality and Policy Implications. Social Indicators 
Research, 108(3), 453-490. doi:10.1007/s11205-011-9887-5

Bhatti, M. (2006). 'When I'm in the garden I can create my own paradise': Homes and gardens in later life. The Sociological Review, 54(2), 318-341. doi:10.1111/j.1467-954x.2006.00616.x

Byles, J., Tavener, M., Robinson, I., Parkinson, L., Smith, P., \& Stevenson, D., ... Curryer, C. (2013). Transforming retirement: New definitions of life after work. Journal of Women \& Aging, 25(1), 24-44. doi:10.1080/08952841.2012.717855

Charles, S. T., \& Carstensen, L. L. (2010). Social and emotional aging. Annual Review of Psychology, 61, 383-409. doi:10.1146/annurev.psych.093008.100448

Clarke, P., Marshall, V., House, J., \& Lantz, P. (2011). The social structuring of mental health over the adult life course: Advancing theory in the sociology of aging. Social Forces, 89(4), 1287-1313. doi:10.1093/sf/89.4.1287

Diener, E. D., Emmons, R. A., Larsen, R. J., \& Griffin, S. (1985). The satisfaction with life scale. Journal of Personality Assessment, 49(1), 71-75.

Dorfman, L. T., \& Douglas, K. (2005). Leisure and the retired professor: Occupation matters. Educational Gerontology, 31, 343-361.

Dow, B., \& Meyer, C. (2010). Caring and retirement: Crossroads and consequences. International Journal of Health Services, 40(4), 645-665. doi:10.2190/hs.40.4.e

Duberley, J., Carmichael, F., \& Szmigin, I. (2013). Exploring women's retirement: Continuity, context and career transition. Gender, Work \& Organization, 21(1), 71-90. doi:10.1111/gwao.12013 
Earl, J. K., Gerrans, P., \& Halim, V. A. (2015) Active and adjusted: Investigating the contribution of leisure, health and psychosocial factors to retirement adjustment. Leisure Sciences: An Interdisciplinary Journal, 4(37), 354-372. doi:10.1080/01490400.2015.1021881

Eleazer, G., Wieland, D., Roberts, E., Richeson, N., \& Thornhill, J. (2006). Preparing Medical Students to Care for Older Adults: The Impact of a Senior Mentor Program. Academic Medicine, 81(4), 393-398. doi:10.1097/00001888-200604000-00015

Eleazer, G., Stewart, T., Wieland, G., Anderson, M., \& Simpson, D. (2009). The National Evaluation of Senior Mentor Programs: Older Adults in Medical Education. Journal of The American Geriatrics Society, 57(2), 321-326. doi:10.1111/j.1532-5415.2008.02100.x Freedman, S. (2009). Effective Mentoring. IFLA Journal, 35(2), 171-182. doi:10.1177/0340035209105672

Grajczyk, A. \& Zöllner, O. (1998). How Older People Watch Television. Gerontology, 44(3), 176-181. doi:10.1159/000022005

Hardy, M. A. (2002). The transformation of retirement in twentieth-century America: From discontent to satisfaction. Generations, 26(2), 9-16.

Heaven, B., Brown, L., White, M., Errington, L., Mathers, J., \& Moffatt, S. (2013). Supporting well-being in retirement through meaningful social roles: Systematic review of intervention studies. Milbank Quarterly, 91(2), 222-287. doi:10.1111/milq.12013

Heckhausen, J., \& Schulz, R. (1995). A life-span theory of control. Psychological Review, $102,284-304$ 
Heflin, M. (2006). The Senior Mentor Program at Duke University School of Medicine. Gerontology \& Geriatrics Education, 27(2), 49-58. doi:10.1300/j021v27n02_06

Hershey, D. \& Henkens, K. (2014). Impact of Different Types of Retirement Transitions on Perceived Satisfaction with Life. The Gerontologist, 54(2), 232-244. doi: 10.1093/geront/gnt006

Houlfort, N., Fernet, C., Vallerand, R., Laframboise, A., Guay, F., \& Koestner, R. (2015). The role of passion for work and need satisfaction in psychological adjustment to retirement. Journal of Vocational Behavior, 88, 84-94. doi:10.1016/j.jvb.2015.02.005

Hoffman, K., Gray, P., Hosokawa, M., \& Zweig, S. (2006). Evaluating the Effectiveness of a Senior Mentor Program. Gerontology \& Geriatrics Education, 27(2), 37-47. doi:10.1300/j021v27n02_05

Information Services Department of Hong Kong (2014). Hong Kong: The Facts: Mandatory Provident Fund. GovHK Fact sheets. Retrieved December 2, 2015, from http://www.gov.hk/en/about/abouthk/factsheets/docs/mpf.pdf

International Business Machines Corporation (2013). IBM SPSS Statistics for Windows, Version 22.0. Armonk, NY: IBM Corp.

Kim, S., \& Feldman, D. C. (2000). Working in retirement: The antecedents of bridge employment and its consequences for quality of life in retirement. Academy of Management Journal, 43, 1195-1210.

Kim, J., \& Moen, P. (2002). Retirement transitions, gender, and psychological well-being: A life-course, ecological model. The Journals of Gerontology Series B: Psychological 
Sciences and Social Sciences, 57(3), 212-222. doi:10.1093/geronb/57.3.p212

Kleiber, D.A., \& Nimord, G. (2008). Expressions of generativity and civic engagement in a 'Learning in Retirement' group. Journal of Adult Development, 15,76-86.

Koc-Menard, S. (2009). Training strategies for an aging workforce. Industrial and Commercial Training, 41(6), 334-338. doi:10.1108/00197850910983938

Kojala, E., \& Moen, P. (2016) No more lock-step retirement: Boomers'shifting meanings of work and retirement. Journals of Aging Studies, 36, 59-70. doi: 10.1016/j.jaging.2015.12.003.

Kraimer, M., Seibert, S., Wayne, S., Liden, R., \& Bravo, J. (2011). Antecedents and outcomes of organizational support for development: The critical role of career opportunities. Journal of Applied Psychology, 96(3), 485-500. doi:10.1037/a0021452

Kuykendall, L., Tay, L., \& Ng, V. (2015). Leisure engagement and subjective well-being: A meta-analysis. Psychological Bulletin, 141(2), 364-403. doi:10.1037/a0038508

Leinonen, T., Lahelma, E., \& Martikainen, P. (2013). Trajectories of antidepressant medication before and after retirement: The contribution of socio-demographic factors. European Journal of Epidemiology, 28(5), 417-26. doi:10.1007/s10654-013-9792-0

Lindbo, T. \& Shultz, K. (1998). The Role of Organizational Culture and Mentoring in Mature Worker Socialization toward Retirement. Public Productivity \& Management Review, 22(1), 49. doi:10.2307/3380589

Lynott, R.T., \& Lynott, P.P. (1996). Tracing the course of theoretical development in the sociology of aging. The Gerontologist, 36(6), 749-760. 
Lyubomirsky, S., Sheldon, K. M., \& Schkade, D. (2005). Pursuing happiness: The architecture of sustainable change. Review of General Psychology, 9, 111-131.

Matz-Costa, C., Besen, E., Boone James, J., \& Pitt-Catsouphes, M. (2014). Differential Impact of Multiple Levels of Productive Activity Engagement on Psychological Well-Being in Middle and Later Life. The Gerontologist, 54(2), 277-289. doi: 10.1093/geront/gns 148

Nathan, A., Wood, L., \& Giles-Corti, B. (2013). Environmental factors associated with active living in retirement village residents: Findings from an exploratory qualitative enquiry. Research on Aging, 35(4), 459-480.

Newman, D., Tay, L., \& Diener, E. (2013). Leisure and Subjective Well-Being: A Model of Psychological Mechanisms as Mediating Factors. Journal of Happiness Studies, 15(3), 555-578.doi:10.1007/s10902-013-9435-X

Ng, S. M., Yau, J. K., Chan, C. L., Chan, C. H., \& Ho, D. Y. (2005). The measurement of body-mind-spirit well-being. Social Work in Health Care, 41(1), 33-52.

Östlund, B. (2009). Watching television in later life: a deeper understanding of TV viewing in the homes of old people and in geriatric care contexts. Scandinavian Journal of Caring Sciences, 24(2), 233-243. doi:10.1111/j.1471-6712.2009.00711.x

Pavot, W., \& Diener, E. (1993). Review of the satisfaction with life scale. Psychological Assessment, 5(2), 164-172.

Petkoska, J., \& Earl, J.K. (2009). Understanding the influence of demographic and psychological variables on retirement planning. Psychology and Aging, 24, 245-251. 
Pinquart, M. \& Schindler, I. (2007). Changes of life satisfaction in the transition to retirement: A latent-class approach. Psychology and Aging, 22(3), 442-455. doi:10.1037/0882-7974.22.3.442

Potočnik, K. \& Sonnentag, S. (2013). A longitudinal study of well-being in older workers and retirees: The role of engaging in different types of activities. Journal of Occupational and Organizational Psychology, 86 (4), 497-521. doi:10.1111/joop.12003

Pushkar, D., Arbuckle, T., Conway, M., Chaikelson, J., \& Maag, U. (1997). Everyday activity parameters and competence in older adults. Psychology and Aging, 12(4), 600-609. doi:10.1037/0882-7974.12.4.600

Pushkar, D., Chaikelson, J., Conway, M., Etezadi, J., Giannopoulus, C., Li, K., \& Wrosch, C. (2009). Testing Continuity and Activity Variables as Predictors of Positive and Negative Affect in Retirement. The Journals Of Gerontology Series B: Psychological Sciences And Social Sciences, 65B(1), 42-49. doi:10.1093/geronb/gbp079

Quick, H. E., \& Moen, P. (1998). Gender, employment, and retirement quality: A life course approach to the differential experiences of men and women. Journal of Occupational Health Psychology, 1, 44-64.

Reitzes, D. C., \& Mutran, E. J. (2004). The transition into retirement: Stages and factors that influence retirement adjustment. International Journal of Aging and Human Development, 59, 63-84.

Reitzes, D., Mutran, E., \& Verrill, L. (1995). Activities and Self-Esteem: Continuing the Development of Activity Theory. Research On Aging, 17(3), 260-277. 
doi:10.1177/0164027595173002

Riley, M., \& Riley, J. (1994). Age integration and the lives of older people. The Gerontologist, 34(1), 110-115. doi:10.1093/geront/34.1.110

Rosenberg, M. (1965). Conceiving the Self. New York: Basic Books.

Rowe, J., \& Kahn, R. (1997). Successful aging. The Gerontologist, 37(4), 433-440. doi:10.1093/geront/37.4.433

Shultz, K. \& Wang, M. (2011). Psychological perspectives on the changing nature of retirement. American Psychologist, 66(3), 170-179. doi:10.1037/a0022411

Snaith, R. P. (2003). The hospital anxiety and depression scale. Health and Quality of Life Outcomes, 1(1), 29.

Sonderen E.v, Sanderman R, Coyne JC (2013) Ineffectiveness of Reverse Wording of Questionnaire Items: Let's Learn from Cows in the Rain. PLoS ONE, 8(7). doi:10.1371/journal.pone.0068967

Sosik, J., \& Godshalk, V. (2000). Leadership styles, mentoring functions received, and job-related stress: A conceptual model and preliminary study. Journal of Organizational Behavior, 21(4), 365-390.

Stancliffe, R., Bigby, C., Balandin, S., Wilson, N., \& Craig, D. (2014). Transition to retirement and participation in mainstream community groups using active mentoring: a feasibility and outcomes evaluation with a matched comparison group. Journal of Intellectual Disability Research, 59(8), 703-718. doi:/10.1111/jir.12174

Stebbins, R. A. (2013). Planning your time in retirement: How to cultivate a leisure lifestyle 
to suit your needs and interests. Lanham, MD: Rowman \& Littlefield.

Stewart, T. \& Alford, C. (2006). Introduction. Gerontology \& Geriatrics Education, 27(2), 3-10. doi:10.1300/j021v27n02_02

Taylor, M. A. \& Doverspike, D. (2003). Retirement planning and preparation. In A. Adams \& Beehr, T. A. (Eds), Retirement: reasons, Processes, and Results (pp.53-82). New York, NY: Spring Publishing Company.

Thornhill, J., Richeson, N., \& Roberts, E. (2002). Senior Mentor Program. Academic Medicine, 77(9), 934-935. doi:10.1097/00001888-200209000-00039

Tkach, C., \& Lyubomirsky, S. (2006). How do people pursue happiness: Relating personality, happiness-increasing strategies, and well-being. Journal of Happiness Studies, 7, $183-225$.

Touvier, M., Bertrais, S., Charreire, H., Vergnaud, A., Hercberg, S., \& Oppert, J. (2010). Changes in leisure-time physical activity and sedentary behavior at retirement: a prospective study in middle-aged French subjects. International Journal of Behavioral Nutrition and Physical Activity, 7(1), 14. doi:10.1186/1479-5868-7-14

van Solinge, H., \& Henkens, K. (2007). Involuntary retirement: The role of restrictive circumstances, timing, and social embeddedness. Journals of Gerontology: Social Sciences, 62B, S295-S303.

van Solinge, H., \& Henkens, K. (2008). Adjustment to and satisfaction with retirement: Two of a kind? Psychology and Aging, 23(2), 422-434. doi:10.1037/0882-7974.23.2.422 
Vo, K., Forder, P., Tavener, M., Rodgers, B., Banks, E., Bauman, A., \& Byles, J. (2014). Retirement, age, gender and mental health: findings from the 45 and Up Study. Aging \& Mental Health, 19(7), 647-657. doi:10.1080/13607863.2014.962002

Waller, K., Kaprio, J., Korhonen, T., Tuulio-Henriksson, A., \& Kujala, U. (2016). Persistent leisure-time physical activity in adulthood and use of antidepressants: A follow-up study among twins. Journal of Affective Disorders, 200, 172-177. doi:10.1016/j.jad.2016.04.036

Wang, H., Koo, B., \& O'Hare, C. (2016). Retirement planning in the light of changing demographics. Economic Modelling, 52, 749-763.

Wang, M. \& Shi, J. (2014). Psychological Research on Retirement. Annual Review of Psychology, 65(1), 209-233. doi:10.1146/annurev-psych-010213-115131

Wang, M. (2007). Profiling retirees in the retirement transition and adjustment process: Examining the longitudinal change patterns of retirees' psychological well-being. Journal of Applied Psychology, 92(2), 455-474. doi:10.1037/0021-9010.92.2.455

Wang, M., Henkens, K., \& van Solinge, H. (2011). Retirement adjustment: A review of theoretical and empirical advancements. American Psychologist, 66(3), 204-213. doi:10.1037/a0022414

Wieldand, G.D., \& Eleazer, G.P. (2006) Senior mentorship in basic medical education developing programs for the teaching of aging. Gerontology \& Geriatrics Education. 27(2): 1-2. doi: 10.1300/J021v27n02_01

Wilson, N., Stancliffe, R., Bigby, C., Balandin, S., \& Craig, D. (2010). The potential for 
active mentoring to support the transition into retirement for older adults with a lifelong disability. Journal of Intellectual and Developmental Disability, 35(3), 211-214. doi: $10.3109 / 13668250.2010 .481784$

Yeung, D. (2013). Is pre-retirement planning always good? An exploratory study of retirement adjustment among Hong Kong Chinese retirees. Aging \& Mental Health, 17(3), 386-393. doi:10.1080/13607863.2012.732036

Zey, M. G. (1991). The mentor connection. New Brunswick: Transaction Publishers. 
Table 1

Means and Standard Deviations of Well-Being Measures of the 161 participants in the

\begin{tabular}{|c|c|c|c|c|c|c|c|c|}
\hline & \multicolumn{2}{|c|}{$\mathrm{T} 1$} & \multicolumn{2}{|c|}{$\mathrm{T} 2$} & \multicolumn{2}{|c|}{$\mathrm{T} 3$} & \multicolumn{2}{|c|}{$\mathrm{T} 4$} \\
\hline Variables & M & SD & M & SD & M & SD & M & $\mathrm{SD}$ \\
\hline Self-esteem & 21.0 & 3.0 & 22.1 & 3.3 & 22.0 & 3.4 & 21.8 & 3.1 \\
\hline Life & 26.5 & 4.9 & 26.8 & 4.4 & 22.3 & 4.1 & 27.1 & 4.8 \\
\hline \multicolumn{9}{|l|}{ satisfaction } \\
\hline Depression & 3.4 & 2.5 & 3.3 & 2.6 & 3.8 & 2.8 & 3.2 & 2.8 \\
\hline Anxiety & 3.9 & 3.2 & 3.2 & 2.8 & 3.8 & 2.9 & 3.1 & 2.9 \\
\hline Physical & 17.6 & 18.3 & 12.5 & 10.5 & 17.3 & 17.6 & 13.5 & 13.5 \\
\hline \multicolumn{9}{|l|}{ Distress } \\
\hline Positive & 59.3 & 10.8 & 64.7 & 10.4 & 64.5 & 11.3 & 66.4 & 9.0 \\
\hline Affect & & & & & & & & \\
\hline
\end{tabular}


Table 2

Paired Sample T Test of Changes from the Baseline of the 161 participants in the Active-interest mentorship program

\begin{tabular}{|c|c|c|c|c|c|c|}
\hline \multirow[b]{2}{*}{ Variables } & \multicolumn{3}{|c|}{ Changes } & \multicolumn{3}{|c|}{ P-Value (Paired with T1) } \\
\hline & $\mathrm{T} 2-\mathrm{T} 1$ & $\mathrm{~T} 3-\mathrm{T} 1$ & $\mathrm{~T} 4-\mathrm{T} 1$ & $\mathrm{~T} 2$ & $\mathrm{~T} 3$ & $\mathrm{~T} 4$ \\
\hline Self-esteem & 1.1 & 1.0 & 0.8 & $.04 *$ & $.05^{*}$ & .08 \\
\hline Life & 0.3 & -4.2 & 0.6 & .62 & $.00 * *$ & .32 \\
\hline \multicolumn{7}{|l|}{ Satisfaction } \\
\hline Depression & -0.1 & 0.4 & -0.2 & .73 & .38 & .55 \\
\hline Anxiety & -0.7 & -0.1 & -0.8 & .10 & .75 & .08 \\
\hline Physical & -5.1 & -0.3 & -4.1 & $.04 *$ & .52 & $.05^{*}$ \\
\hline \multicolumn{7}{|l|}{ Distress } \\
\hline Positive & 5.4 & 5.2 & 7.1 & $.01 * *$ & $.02 *$ & $.00 * *$ \\
\hline Affect & & & & & & \\
\hline
\end{tabular}

$* \mathrm{p} \leq .05 . * \mathrm{p} \leq .01$. 
Figure 1. Variables' percentage of changes at T2, T3, and T4 over T1. (page.12)

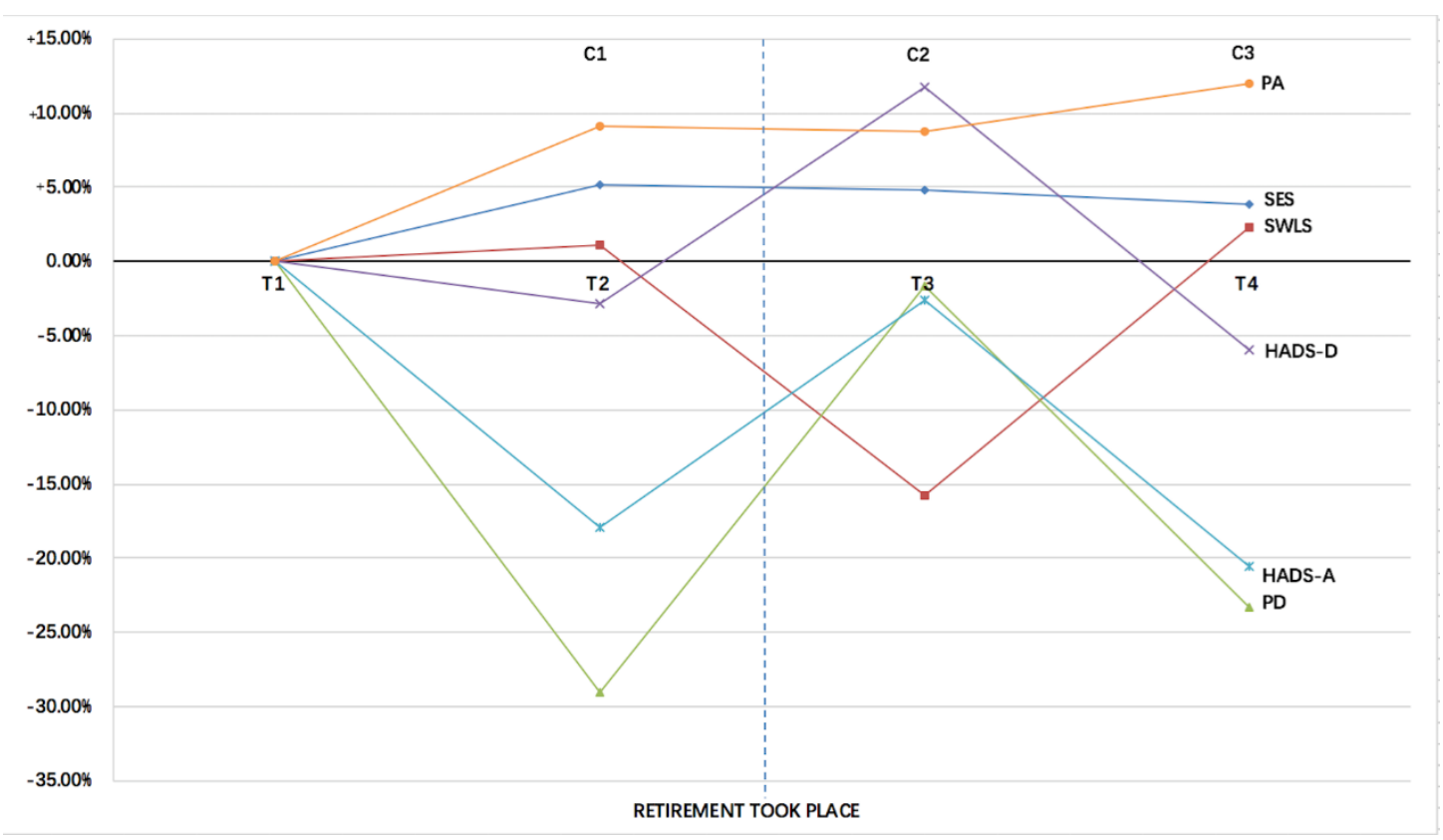

Captions :

1. $\mathrm{C} 1$ denotes percentage change f3rom $\mathrm{T} 1$ to $\mathrm{T} 2$; $\mathrm{C} 2$ denotes percentage change from $\mathrm{T} 1$ to $\mathrm{T} 3$; $\mathrm{C} 3$ denotes percentage change from $\mathrm{T} 1$ to $\mathrm{T} 4$.

2. $\mathrm{SES}=$ Self-esteem Scale; $\mathrm{SWLS}=$ Satisfaction with Life Scale $\mathrm{PD}=$ Physical Distress; HADS-D = HADS Depression subscale; HADS-A = HADS Anxiety subscale; PA $=$ Positive Affects . 